\title{
X-RAY ANALYSIS FOR DETERMINATION THE CRYSTALLITE SIZE AND LATTICE STRAIN IN ZnO NANOPARTICLES
}

\author{
H. S. Wasly \\ Mining, Metallurgy and Petroleum Engineering Department, Faculty of Engineering, \\ Al-Azhar University, Qena, Egypt.
}

\begin{abstract}
Zinc oxide $(\mathrm{ZnO})$ nanoparticles were synthesized by modified hydrothermal method at $160^{\circ} \mathrm{C}$ under different reaction times. The analysis of the XRD pattern lines is considered a simple and effective method in estimating the crystallite size and the corresponding lattice strain. Xray patterns were analyzed using Scherrer method and Williamson-Hall treatment to determine the crystallite size and the lattice strain. The XRD pattern confirmed the presence of crystalline hexagonal wurtzite $\mathrm{ZnO}$ nanoparticles with average crystallite size in the range $30-36 \mathrm{~nm}$ with different reaction times. $\mathrm{ZnO}$ nanoparticles were also characterized by high resolution transmission electron microscopy (HR-TEM), UV-visible spectroscopy and thermal analysis.
\end{abstract}

KEYWORDS: Zno Nanoparticles; X-Ray Peak Analysis; Lattice Strain; Williamson-Hall Treatment

\section{INTRODUCTION}

Metal oxide nanomaterials have taken great interest due to their particular properties and wide applications in different areas [1]. ZnO is non-hazardous, chemically stable and easy to synthesis, also has good optical and piezoelectric properties. $\mathrm{ZnO}$ is a semiconductor metal oxide and considered as n-type semiconductor [2]. It has become an important future material and has gained specific interest in the scientific research [3-6]. It is used as an additive in many products like cement, ceramics, adhesives, glass, paints, plastics, pigments, batteries, ferrites, rubber, fire retardants, lubricants, first aid tapes, food (source of Zn nutrient) [7-9].

Different methods have been used to synthesis $\mathrm{ZnO}$ nanoparticles as hydrothermal reaction, sol gel synthesis, and chemical precipitation. Hydrothermal method is viewed as a characteristic alternative method in the synthesis of nanomaterials for its important advantages. It is a low process temperature method, simple apparatus employment, low process expenditure, and environmental friendliness [10-12]. The analysis of X-ray line broadening has been applied to estimate the crystallite size and lattice strain [13]. Different methods, as Williamson-Hall [14] and Halder-Wagner procedures [15], are applied for determining the grain size and the corresponding strain [13].

In the present work $\mathrm{ZnO}$ nanoparticles were synthesized using hydrothermal method under various reaction times. From X-ray diffraction patterns using Scherrer and Williamson-Hall methods, the grain size and the equivalent strain could be determined. The morphology, UVvisible spectroscopy and thermal analysis of the obtained nanoparticles were studied to characterize them.

\section{Experimental Work}

\subsection{ZnO Nanoparticles synthesis}

For obtaining $\mathrm{ZnO}$ nanoparticles the following materials were used: Zinc acetate di-hydrate $\left[\mathrm{Zn}\left(\mathrm{Ch}_{3} \mathrm{COO}\right)_{2} .2 \mathrm{H}_{2} \mathrm{O}\right]$ and sodium hydroxide $[\mathrm{NaOH}]$. The reaction agents were used as 
received without further purification. A known ratios of Zinc acetate di-hydrate and sodium hydroxide were dissolved in distilled water. Followed by dropping of $\mathrm{NaOH}$ solution in slow rate into the Zinc acetate solution under stirring. The reaction mixture was continuously stirred and heated for $2 \mathrm{~h}$ using a hot plate agitator, and a white precipitation was formed. The mixture was transferred to a Teflon lined stainless steel autoclave for hydrothermal treatment at a temperature $160{ }^{\circ} \mathrm{C}$ for different times $7,15,23 \mathrm{hrs}$., then the autoclave was allowed to cool down naturally to room temperature. After the reaction was completed, the resulting white precipitate was separated by centrifuge and washed several times with ethanol and distilled water, and then dried in air in a laboratory oven at $75{ }^{\circ} \mathrm{C}$ for 6 hours to remove the organic impurities.

\subsection{Characterization}

The crystalline structures of the prepared powders were analyzed by X-ray diffractometry (XRD) (X'Pert PRO, PANalytical, Netherlands) using $\mathrm{Cu} \mathrm{K \alpha}$ radiation $(\lambda=1.5406 \AA$ ) in the angular region of $2 \theta=20^{\circ}-70^{\circ}$. The instrument was operated at $40 \mathrm{kV}$ and the spectra were recorded at scanning speed of $8 \% \mathrm{~min}$. Smaller angular steps of $\left(2 \theta=0.02^{\circ}\right)$ was taken to measure the intensity of each Bragg reflection. For determining the crystallite size and the corresponding lattice strain, the analysis of the XRD pattern lines is necessary and effective [16-17]. The strain resulted in the $\mathrm{ZnO}$ nanoparticles, that is attributed to the deformation in the lattice, could be determined by using Williamson-Hall $(\mathrm{W}-\mathrm{H})$ method [18-19]. The crystallite size (D) and the lattice strain were estimated using Scherer's equation and W-H method. The morphology of the obtained $\mathrm{ZnO}$ nanoparticles was characterized with high resolution transmission electron microscope (HR-TEM), (JEOL, JEMA 2100-Japan), performed at $200 \mathrm{kV}$. For optical studies, (JASCO $670 \mathrm{UV}$ ) spectrophotometer was used to measure the spectrum of the samples. To study the thermal stability of the synthesized $\mathrm{ZnO}$ nanoparticles, about $25 \mathrm{mg}$ of the samples were heated using LINSEIS STA PT-1000 with a heating rate $10{ }^{\circ} \mathrm{C} / \mathrm{min}$ up to $800{ }^{\circ} \mathrm{C}$.

\section{RESULTS AND DISCUSSION}

\subsection{X-ray diffraction studies}

$\mathrm{X}$-ray diffraction patterns of the $\mathrm{ZnO}$ nanoparticles synthesized by hydrothermal process at different periods $7,15,23 \mathrm{hrs}$., $\left(\mathrm{S}_{1}-\mathrm{S}_{3}\right)$ are shown in Fig. 1 . XRD patterns applied according to Bragg's law $(\lambda=2 \mathrm{~d} \sin \theta)$, where $\lambda$ is the wavelength of $\mathrm{Cu}$ radiation, $\mathrm{d}$ is the interplanar spacing and $\theta$ is the diffraction angle [16-17]. The XRD spectra indicate that the $\mathrm{ZnO}$ crystal has a hexagonal structure, with lattice constants $\mathrm{a}=\mathrm{b}=0.3251 \mathrm{~nm}$ and $\mathrm{c}=0.5212 \mathrm{~nm}$ as in standard JCPDS data (No. 36-1451).

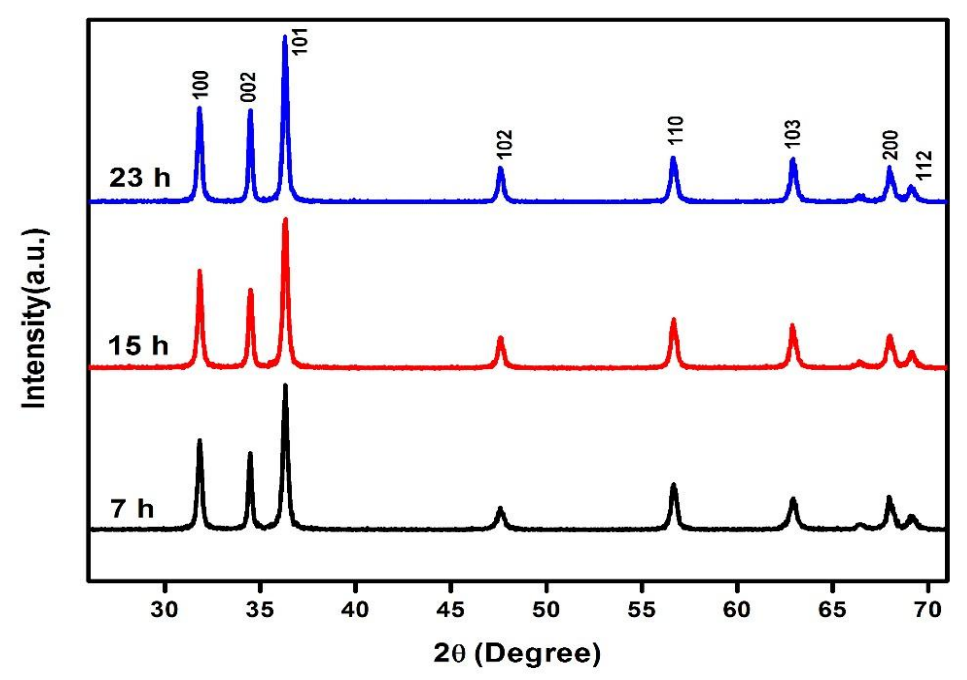

Fig. 1 XRD spectrum of $\mathrm{ZnO}$ nanoparticles under different times 7, 15, $23 \mathrm{hrs}$. 
The XRD pattern of the obtained $\mathrm{ZnO}$ nanoparticles does not contain any peaks other than $\mathrm{ZnO}$ peaks, which means that the obtained $\mathrm{ZnO}$ nanoparticles were free of impurities. From XRD pattern, the synthesized $\mathrm{ZnO}$ nanoparticles lattice constants (a and c) were calculated from equation (1) using the interplanar distance $\mathrm{d}$ and (hkl) values of the XRD profile $[20,12]$.

$$
\frac{1}{d^{2}}=\frac{4}{3}\left[\frac{h^{2}+h k+l^{2}}{a^{2}}\right]+\frac{l^{2}}{c^{2}}
$$

The volume of the nanoparticles has been calculated from the relation [20]:

$$
\mathrm{V}=(4 / 3) \pi(\mathrm{D} / 2)^{3}
$$

and the volume of hexagonal unit cell from the equation:

$$
\mathrm{v}=\left(3 \mathrm{a}^{2} \mathrm{c}\right) / 2
$$

Then, the proportion $\mathrm{V} / \mathrm{v}$ gives the number of unit cell existent in a particle, which can be calculated from the equation [20]:

$$
\mathrm{n}=1.621\left(\mathrm{D}^{3} / \mathrm{a}^{2} \mathrm{c}\right)
$$

From the V/v ratio number of the unit cell present in a particle for the samples $7 \mathrm{~h}, 15 \mathrm{~h}, 23 \mathrm{~h}$ $\left(\mathrm{S}_{1}-\mathrm{S}_{3}\right)$ are found to be $(904682,1084521,1266016)$ respectively.

The average distance between nuclei of two bonded atoms in a molecule is known as the bond length or bond distance. Bond length is related to bond order, i.e. the bond is shorter, when more electrons contribute in bond formation. Bond length is inversely proportional to bond strength and the bond dissociation energy. By using XRD, the bond lengths are measured in the solid phase. The $\mathrm{Zn}-\mathrm{O}$ bond length (L) has been calculated by the relation [21];

$$
\mathrm{L}=\sqrt{0.3 a^{2}+(0.5-u)^{2} C^{2}}
$$

Where, $\mathbf{u}$ is known as internal parameter (z-coordinate of the oxygen atoms) of the wurtzite structures $\left(\mathrm{u}=\mathrm{a}^{2} / 3 \mathrm{c}^{2}+0.25\right)$. $\mathrm{Zn}-\mathrm{O}$ bond length was found to be $(1.9773 \AA)$, for all the samples of reaction time of 7,15 and $23 \mathrm{hrs}\left(\mathrm{S}_{1}-\mathrm{S}_{3}\right)$. Table 1 shows the characteristics of the $\mathrm{ZnO}$ nanoparticles synthesized at various time values.

\subsection{Crystallite size and the lattice strain calculations}

The average crystallite size, $\mathrm{D}$, of the $\mathrm{ZnO}$ nanoparticles was calculated by using Scherrer formula [22]:

$$
(\mathrm{D}=\mathrm{k} \lambda / \beta \cos \theta)
$$

where, $\mathrm{k}$ is a shape factor (0.9), $\lambda$ is the $\mathrm{Cu} \mathrm{k} \alpha$ radiation wavelength $(1.54060 \AA), \beta$ is the peak width at half maximum (in radians) and $\theta$ is Bragg's diffraction angle. The average values of the crystallite size, $\mathrm{D}$, of the $\mathrm{ZnO}$ nanoparticles synthesized via hydrothermal process at different reaction times 7, 15 and 23 hours, are shown in Table 1.

To evaluate the created strain in the samples of $\mathrm{ZnO}$ nanoparticles as a result to the deformation in the lattice, Williamson-Hall method were applied from the following equation:

$$
\beta \cos \theta=\frac{\mathrm{k} \lambda}{D}+4 \varepsilon \sin \theta
$$

By plotting $4 \sin \theta$ along the $\mathrm{x}$-axis and $\beta \cos \theta$ along the $\mathrm{y}$-axis and from the linear fit of the data (using the Originpro 8 software), the crystallite size was estimated from the yintercept, and the strain $\varepsilon$, from the slope [14,23]. Figure 2 displays plotting of $\mathbf{4} \sin \boldsymbol{\theta}$ against $\boldsymbol{\beta} \cos \boldsymbol{\theta}$ for the samples of $\mathrm{ZnO}$ nanoparticles at different reaction times $\left(\mathrm{S}_{1}-\mathrm{S}_{3}\right)$. Crystallite size values for the synthesized samples determined by Scherer and $\mathrm{W}-\mathrm{H}$ methods are displayed in Table 1. Figure 3 shows the variation of the crystallite size obtained by Scherrer and W-H methods, from which it is obvious that the average crystallite size 
slightly increases with the increase of the reaction time. This may be due to increasing of nucleation and growth rate of nanoparticles [20].

Table 1. The characteristics of the $\mathrm{ZnO}$ nanoparticles synthesized at various time values.

\begin{tabular}{|c|c|c|c|c|c|c|c|c|}
\hline \multirow{2}{*}{ sample } & \multicolumn{2}{|c|}{ D (nm) } & \multirow{2}{*}{$\underset{(\mathbf{n m})}{\mathbf{d}}$} & \multirow{2}{*}{$\underset{\left(10^{-3}\right)}{\varepsilon}$} & \multirow{2}{*}{$\underset{(\mathbf{n m})}{\mathbf{a}}$} & \multirow{2}{*}{$\begin{array}{c}\mathbf{c}, \\
(\mathbf{n m})\end{array}$} & \multirow{2}{*}{$\begin{array}{l}\text { unit cell No. } \\
\text { (n) }\end{array}$} & \multirow{2}{*}{$\begin{array}{c}\text { bond length } \\
(\mathrm{L}, \AA)\end{array}$} \\
\hline & Scherer & WH & & & & & & \\
\hline $7 \mathrm{~h}$ & 30.20 & & 0.2475 & 1.1075 & 0.3249 & 0.5205 & & 1.9773 \\
\hline $15 \mathrm{~h}$ & 32.25 & 45. & 0.24 & & & 0.5 & & \\
\hline $23 \mathrm{~h}$ & 34.06 & 48.76 & 0.2475 & 0.9902 & 0.3249 & 0.5205 & 1266016 & 1.9773 \\
\hline
\end{tabular}
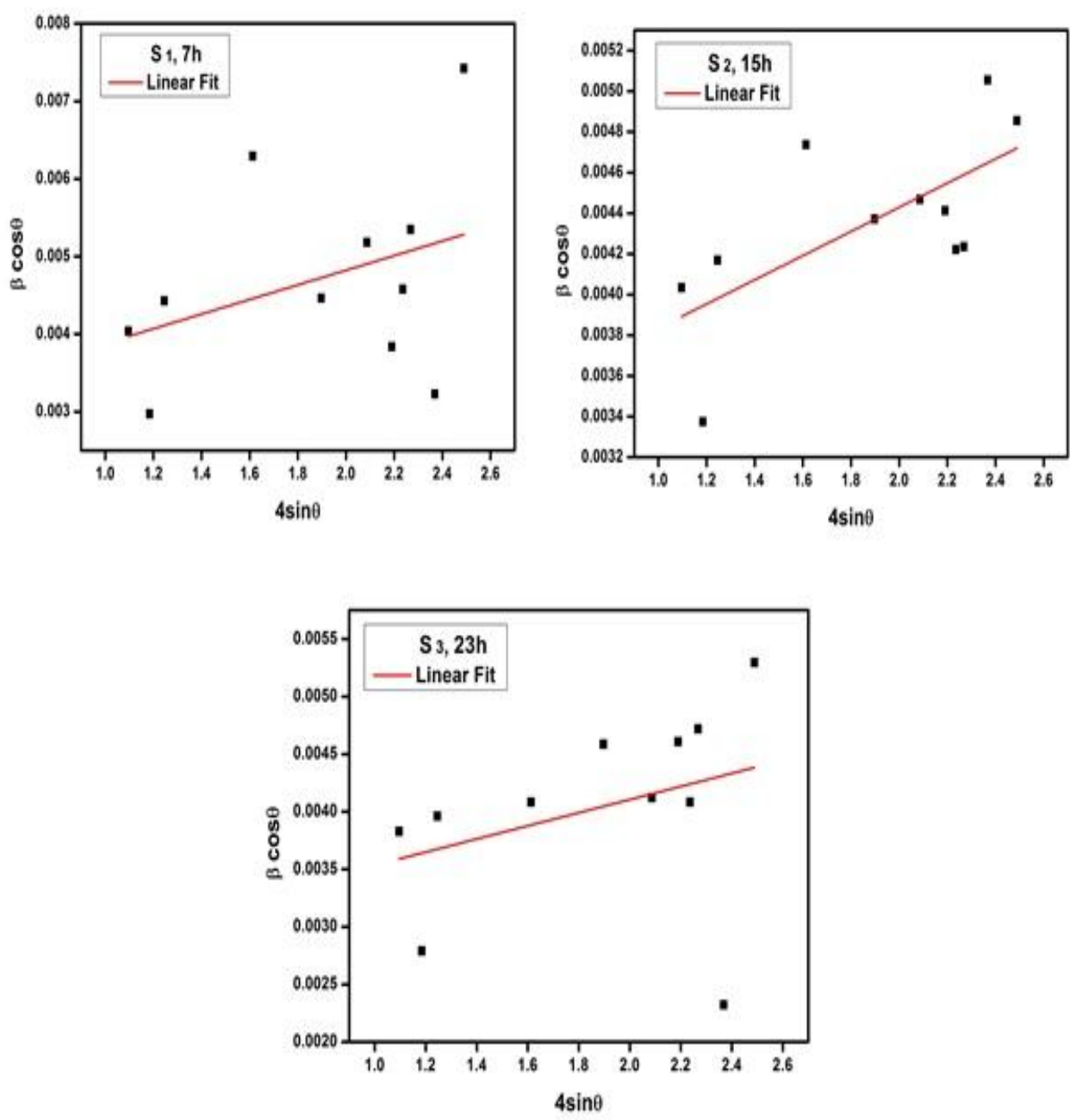

Fig.2 plotting of $\beta \cos \theta$ vs $4 \sin \theta$ of $\mathrm{W}-\mathrm{H}$ analysis, for $\mathrm{ZnO}$ nanoparticles $\left(\mathrm{S}_{1}-\mathrm{S}_{3}\right)$.

Also, it is clear that the crystallite size calculated from XRD data using Scherrer equation is smaller than crystallite size determined from Williamson-Hall method. This may be due to the fact that the Scherrer method actually measures the coherence length of the X-rays, any crystal imperfections will cause the calculated size to be smaller than the true size but in WH method the microstrain effect was taken into consideration [24]. 


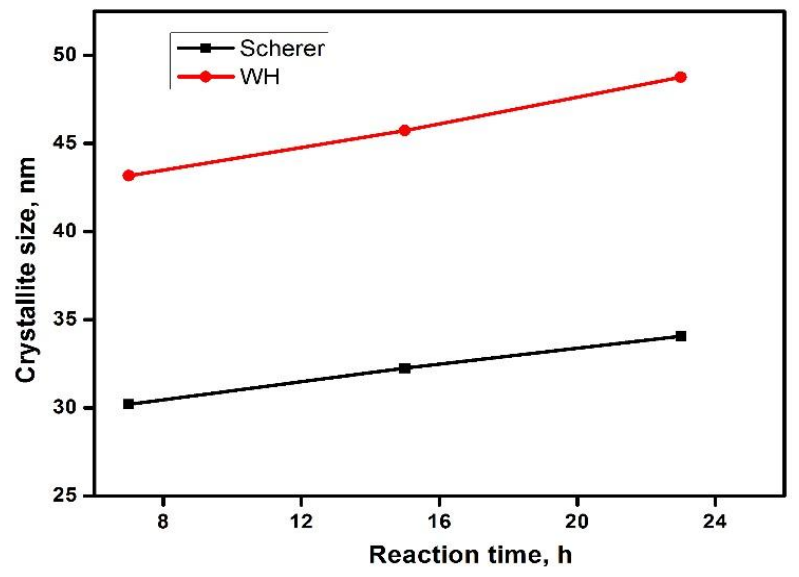

Fig. 3 crystallite size obtained by Scherrer and $\mathrm{WH}$ methods for $\mathrm{ZnO}$ nanoparticles $\left(\mathrm{S}_{1}-\mathrm{S}_{3}\right)$.

\subsection{HR-TEM analysis}

To investigate the shape and size of the obtained $\mathrm{ZnO}$ nanoparticles with different reaction times, HR-TEM was carried out (Figure 4).
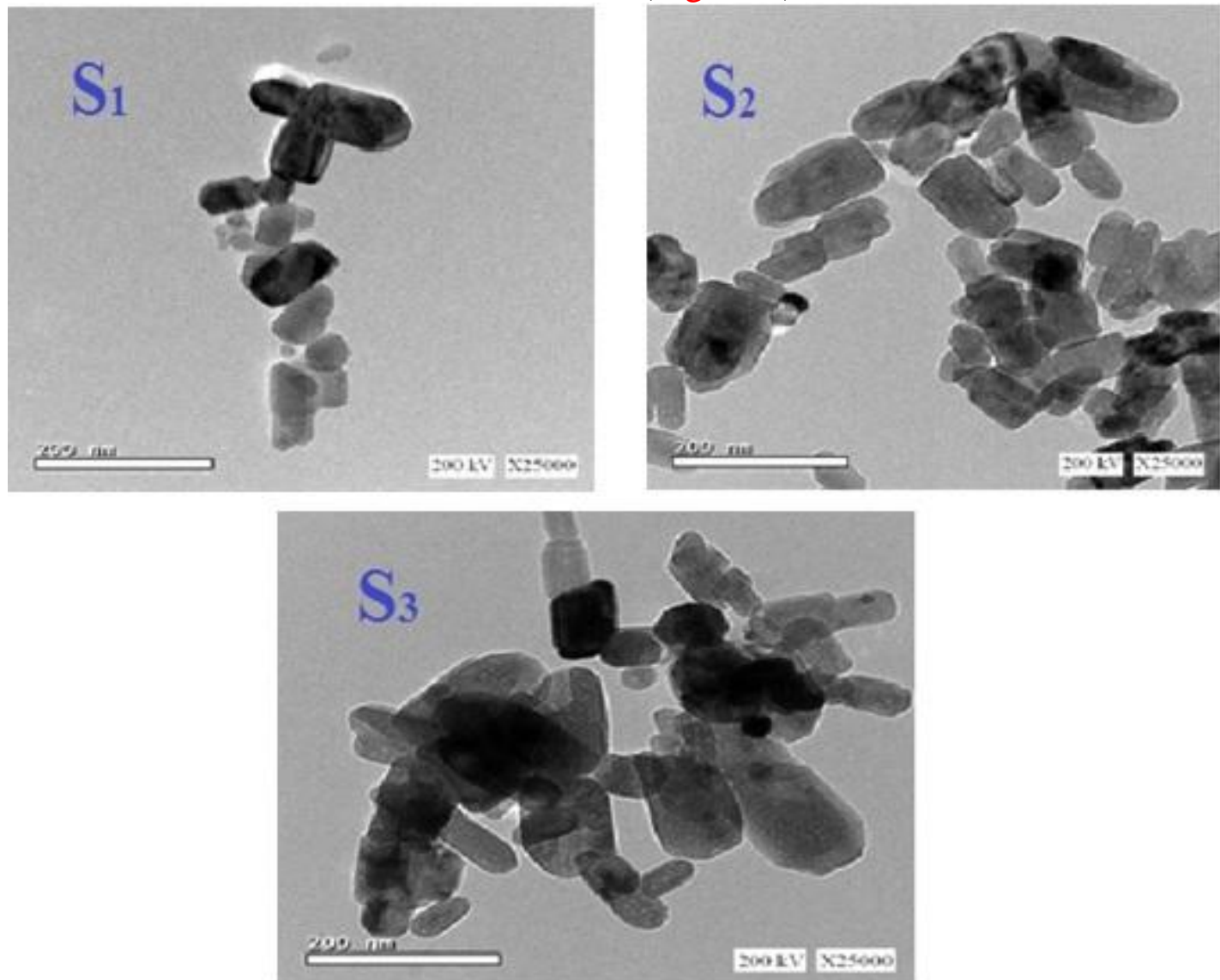

Fig. 4 HR-TEM images of $\mathrm{ZnO}$ nanoparticles synthesized at various reaction times $\left(\mathrm{S}_{\mathbf{1}}-\mathrm{S}_{\mathbf{3}}\right)$.

The reaction time has an observed effect on the shape and the size of the obtained $\mathrm{ZnO}$ nanoparticles. With increasing the reaction time spherical-like and rod shapes of $\mathrm{ZnO}$ nanoparticles were obtained due to the increase of the growth rate (Figure 4). Also, approximately all the $\mathrm{ZnO}$ nanoparticles appeared in clusters of nanorods shape due to smaller nanoparticles collecting and forming larger particles [12]. 


\subsection{Optical properties}

The optical absorption and transmittance spectra of the prepared samples at near normal incidence over a spectral ranging between 200 and $800 \mathrm{~nm}$ for times 7, 15, 23 hours are displayed in Fig.5.
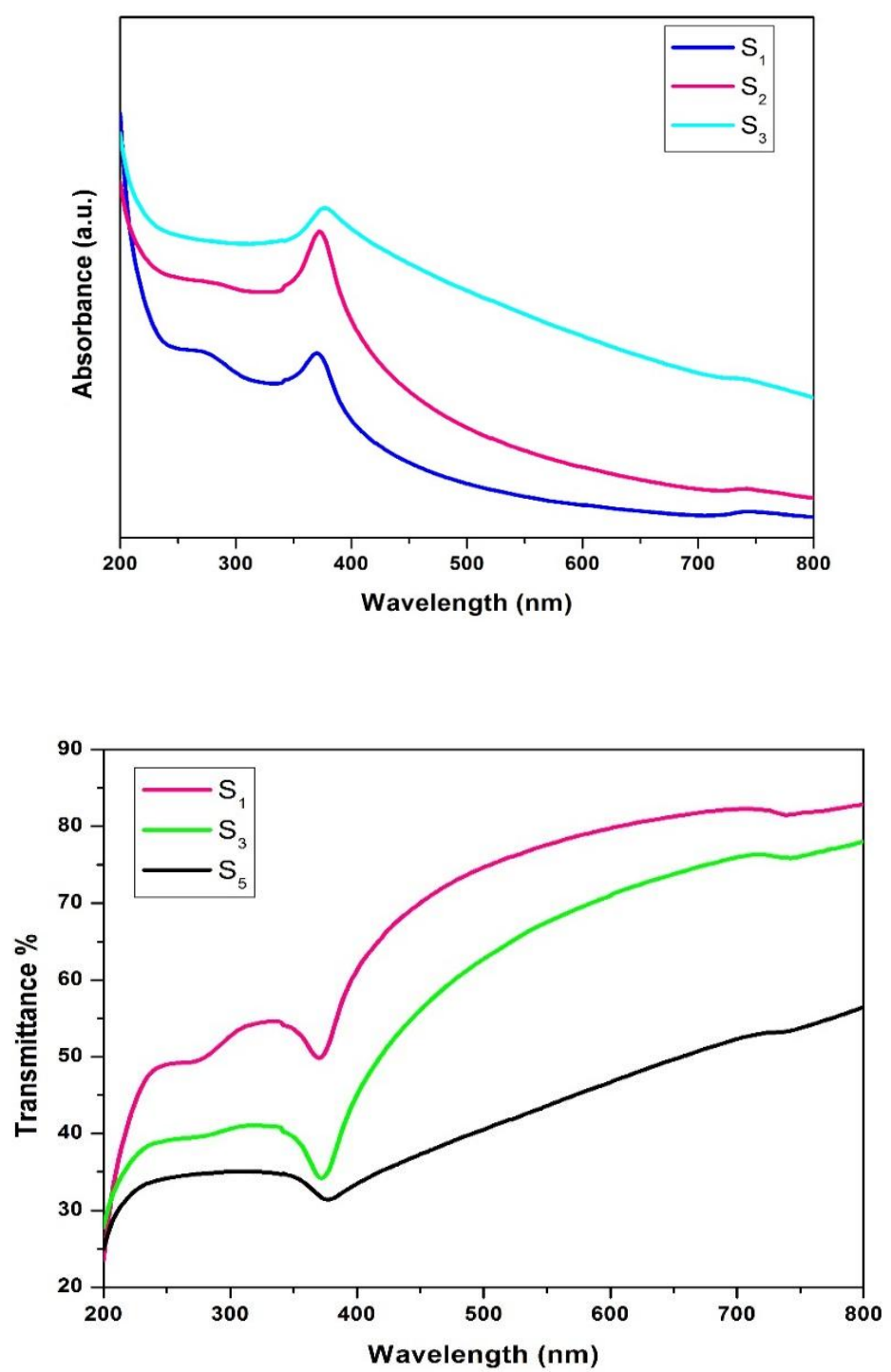

Fig. 5 Absorbance and transmittance spectra of $\mathrm{ZnO}$ nanoparticles synthesized at different times.

The direct optical band gap with direct transition can be calculated using the relation:

$$
\alpha \mathrm{h} v=\mathrm{B}\left(\mathrm{h} v-\mathrm{E}_{\mathrm{g}}\right)^{1 / 2}
$$

where $\mathbf{h v}$ is the photon energy and $\mathbf{B}$ is a constant that depends on the transition probability, $\boldsymbol{\alpha}$ is the absorption coefficient and $\mathbf{E}_{\mathbf{g}}$ is the optical band gap. From Fig. 6 the energy gap $\left(\mathbf{E}_{\mathbf{g}}\right)$ can be estimated from the plot of $\mathbf{h v}$ against $(\boldsymbol{\alpha h v})^{2}$. The values of $\mathbf{E}_{\mathbf{g}}$ are 3.58, 3.14, $2.90 \mathrm{eV}$ for $\left(\mathrm{S}_{1}-\mathrm{S}_{3}\right)$ respectively, and depend on the reaction time. The determined values are different from that of the bulk $\mathrm{ZnO}(3.37 \mathrm{eV})$. This blue shift may be attributed to quantum confinement effects in the prepared zinc oxide samples [25, 20]. It can be noticed that with increasing the reaction time, the band gap value decreases due to the increase of the crystallite size. This confirms that the above behavior may be due to increasing of nucleation and growth rate of nanoparticles [12,20]. 


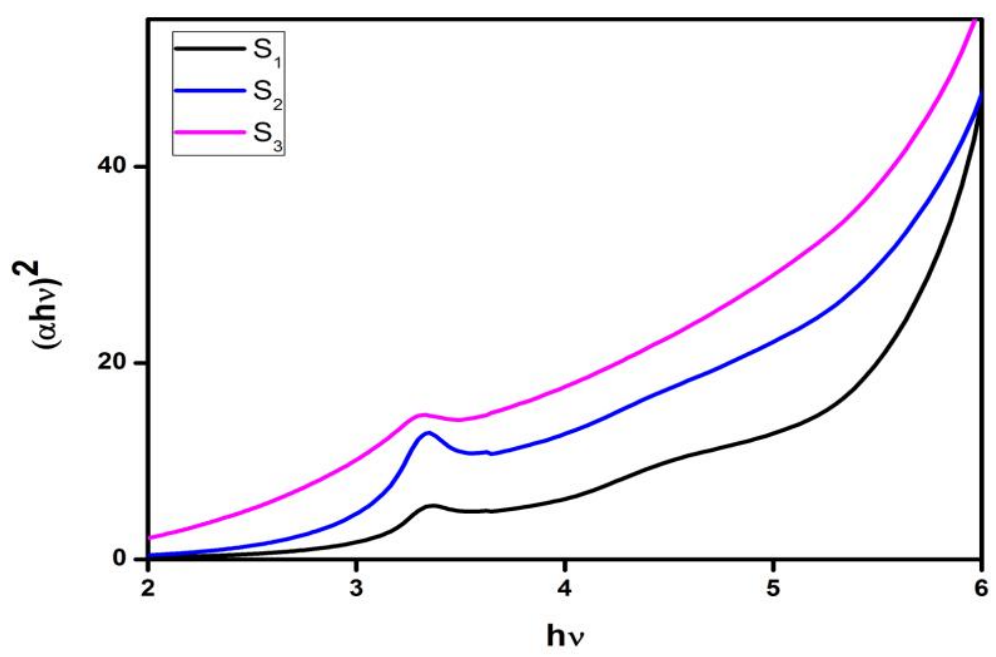

Fig. 6 Plots of $\mathrm{h} \gamma$ against $(\alpha \mathrm{h} \gamma)^{2}$ of $\mathrm{ZnO}$ nanoparticles synthesized at different times.

\subsection{Thermal analysis}

The differential scanning calorimetry (DSC) of the obtained $\mathrm{ZnO}$ nanoparticles under different reaction times is displayed in Fig. 7.

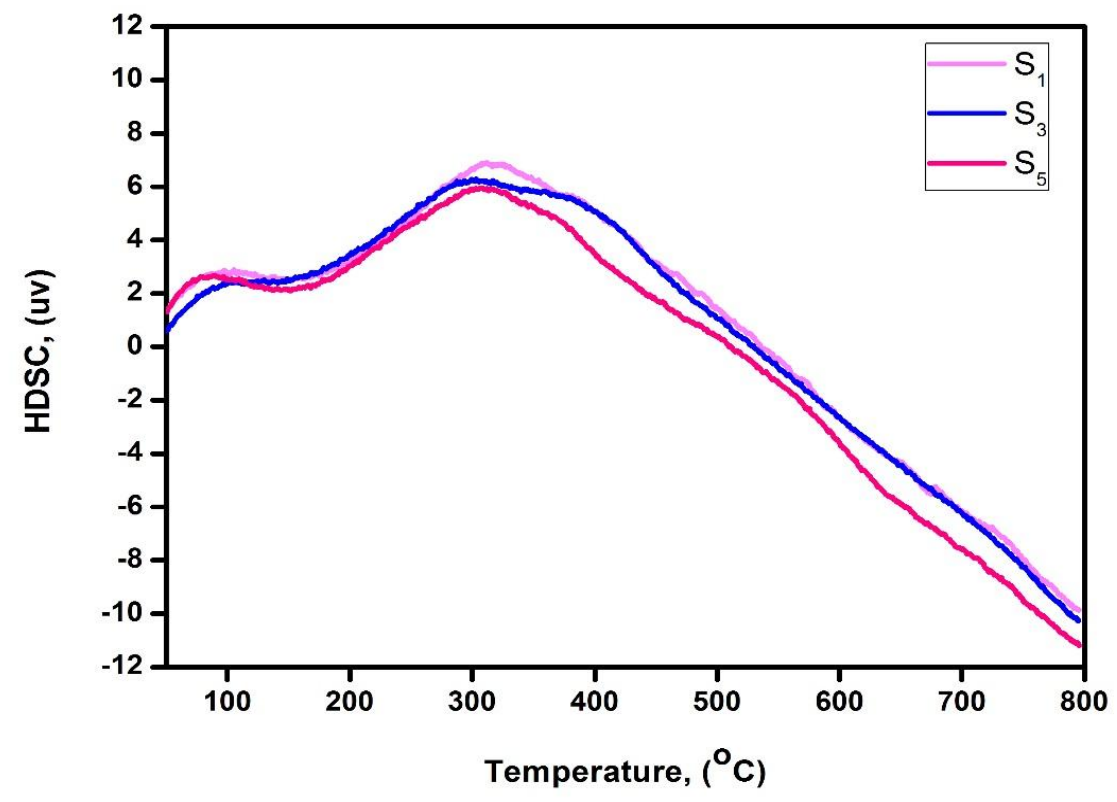

Fig. 7 DSC of ZnO nanoparticles synthesized at different times 7, 15, $23 \mathrm{~h}$.

Two types of peaks are observed, the first one occurs at around $145^{\circ} \mathrm{C}$ and is weak. This type is attributed to an activation energy involving an endothermic reaction. The second type of peaks occurred at two temperatures; around $310{ }^{\circ} \mathrm{C}$ (the broad) and around $100{ }^{\circ} \mathrm{C}$. They represent an exothermic reaction that may be due to the burn-out of organic composition. According to the change of phases at the mentioned temperature ranges, both peaks groups are created [26-28].

\section{CONCLUSIONS}

The $\mathrm{ZnO}$ nanoparticles have been successfully synthesized by a modified hydrothermal method and characterized by XRD and different techniques. From diffraction patterns, using Scherrer and Williamson-Hall method, the grain size and the equivalent strain could be determined. The average values of the crystallite size, $\mathrm{D}$, of the $\mathrm{ZnO}$ nanoparticles 
synthesized via hydrothermal process at different reaction times are in the range 30-34 nm. The morphology showed that with increasing the reaction time, smaller nanoparticles combined themselves and formed larger particles and the average size of the $\mathrm{ZnO}$ nanoparticles is in in agreement with XRD calculations. The blue shift of the absorption of $\mathrm{ZnO}$ in the UV-Vis spectra was gradually increased with the increase in reaction time due to the decrease of particle size. DSC of $\mathrm{ZnO}$ samples indicates endothermic reactions and exothermic reactions which are due to change of phases at those temperatures.

\section{Acknowledgements}

The author would like to express his gratitude to Al-Azhar University for providing administrative and technical support.

\section{REFERENCES}

1. D. A. M. Osman, M. A. Mustafa "Synthesis and Characterization of Zinc Oxide Nanoparticles using Zinc Acetate Dihydrate and Sodium Hydroxide" Journal of Nanoscience and Nanoengineering, Vol. 1, No. 4, (2015): 248-251

2. Z. L. Wang, "Nanostructures of zinc oxide", Materials Today, 7(6), (2004): 26-33.

3. N. A. Salahuddin, M. El-Kemary, E. M. Ibrahim "Synthesis and Characterization of ZnO Nanotubes by Hydrothermal Method" International Journal of Scientific and Research Publications, Volume 5, Issue 9, September (2015), ISSN 2250-3153.

4. A. B. Djurisic and Y. H. Leung, "Optical properties of $\mathrm{ZnO}$ nanostructures." Small, 2(8-9), (2006): 944-961.

5. M. Kumar, S. Kumar, Z. Parveen, J. Kaur, N. sharma, Babankumar" Facial Synthesis of Nano Sized ZnO by Hydrothermal Method" International Journal of Advanced Research in Electrical, Electronics and Instrumentation Engineering (An ISO 3297: 2007 Certified Organization), 4(5), May (2015).

6. H. P. Suryawanshi, S. G. Bachhav, D. R. Patil" Hydrothermal Synthesis of Zinc Oxide and Its Photocatalytic Effect" International Journal of Chemical and Physical Sciences, IJCPS Vol. 4 Special Issue - NCSC Jan-(2015), ISSN:2319-6602.

7. A. K. Barve, S. M. Gadegone, M. R. Lanjewar, and R. B. Lanjewar" Synthesis of ZnO nanomaterial by Precipitation Method and its Characterization” International Journal of Chemical and Physical Sciences, ISSN:2319-6602, IJCPS Vol. 4 Special Issue - NCSC Jan-(2015).

8. A. Benazir, K. Gomathi, S. Aram "Structural and Optical Properties of Zn1-xNixO Nanoparticles Synthesized by Co-precipitation Method" J. Environ. Nanotechnol., Vol. 6(1), (2017): 39-43

9. S. Sharma, S. C. Bhandari, S. P. Shrestha, L. P. Joshi” Synthesis and study of zinc oxide nanoparticles for dye sensitized solar cell" Research Journal of Physical Sciences, Vol. 5(5), June (2017): 6-10.

10. H. P. Suryawanshi, S. G. Bachhav, D. R. Patil "Hydrothermal Synthesis of Zinc Oxide and Its Photocatalytic Effect", IJCPS 4 (2015): 483-486

11. B. Sunandan, D. Joydeep "Hydrothermal growth of $\mathrm{ZnO}$ nanostructure", Sci. Technol. Adv. Mater. 10 (2009): 1-18.

12. S. Sabita, C. B. Subash, P. S. Shankar, P.J. Leela "Synthesis and study of zinc oxide nanoparticles for dye sensitized solar cell" Research Journal of Physical Sciences, 5 (2017): 6-10.

13. A. E. Mahmoud, H. S. Wasly, M. A. Doheim "Studies of crystallite size and lattice strain in $\mathrm{Al}-\mathrm{A} 12 \mathrm{O} 3$ powders produced by high-energy mechanical milling". J Eng. Sci., 42, (2014): 1430-9.

14. G. K. Williamson, WH. Hall. "X-ray line broadening from filed aluminum and wolfram" Acta metallurgica. 1;1(1), (1953) Jan:22-31.

15. J.I. Langford "A rapid method for analyzing the breadths of diffraction and spectral lines using the Voigt function" Journal of Applied Crystallography. 1;11(1), (1978) Feb:10-4.

16. K. Venkateswarlu, A.C. Bose, N. Rameshbabu "X-ray peak broadening studies of nanocrystalline hydroxyapatite by Williamson-Hall analysis" Physica B: Condensed Matter. 15;405(20), (2010) Oct:4256-61. 
17. V. S. Kumar, K.V. Rao "X-ray Peak Broadening Analysis and Optical Studies of ZnO Nanoparticles Derived by Surfactant Assisted Combustion Synthesis". Journal of Nanoand Electronic Physics. 1;5(2), (2013) Apr:2026-1.

18. K. Ramakanth "Basics of X-ray Diffraction and its Application" I.K. International Publishing House Pvt. Ltd.: New Delhi: (2007)

19. P. Bindu, S. Thomas "Estimation of lattice strain in $\mathrm{ZnO}$ nanoparticles: X-ray peak profile analysis" Journal of Theoretical and Applied Physics. 1;8(4), (2014) Dec:123-34.

20. C. M. Jay, M. Sathya, K. Pushpanathan "Effect of $\mathrm{pH}$ on Crystal Size and Photoluminescence Property of $\mathrm{ZnO}$ Nanoparticles Prepared by Chemical Precipitation Method" Acta Metall. Sin. (Engl. Lett.), 28, (2015): 394-404.

21. C. S. Barret, T.B. Massalski "Structure of Metals" Pergamon Press, Oxford, (1980)

22. V. D. Mote, Y. Purushotham, B. N. Dole "Williamson-Hall analysis in estimation of lattice strain in nanometer-sized $\mathrm{ZnO}$ particles" Journal of Theoretical and Applied Physics. 1;6(1), (2012) Dec:6.

23. T. Pandivaraian, B. Karthikeyan "Cr doping induced structural, phonon and excitonic properties of $\mathrm{ZnO}$ nanoparticles" Journal of Nanoparticle Research. 1;14(1), (2012):647

24. J. Markmann, V. Yamakov, Weissemu“ller."Validating grain size analysis from X-ray line broadening: A virtual experiment" J. Scr. Mater. 59, (2008): 15-18.

25. S.N. Shaha, I.S. Alib, A.S. Rizwan, M. Naeema, B. Yasmeen, S.A. Rehan, S.R. Masood, K. Yousuf, K. S. Sikander, "Synthesis and Characterization of Zinc Oxide Nanoparticles for Antibacterial Applications" Journal of Basic \& Applied Sciences, 12, (2016): 205-210.

26. J.N. Hasnidawani, H.N. Azlina, H. Norita, N.N. Bonnia, S. Ratim, E.S. Ali "Synthesis of ZnO Nanostructures Using Sol-Gel" Procedia Chemistry 19, (2016): 211-216.

27. N.A. Salahuddin, M. El-Kemary, E.M. Ibrahim "Synthesis and Characterization of ZnO Nanoparticles via Precipitation Method: Effect of Annealing Temperature on Particle Size" Nanoscience and Nanotechnology, 5, (2015): 82-88.

28. S. Klubnuan, P. Amornpitoksuk, S. Suwanboon "Structural, optical and photocatalytic properties of $\mathrm{MgO} / \mathrm{ZnO}$ nanocomposites prepared by a hydrothermal method" Materials Science in Semiconductor Processing 39, (2015): 515-520. 